\title{
Lessons of the month 3: Intravenous poppers abuse: case report, management and possible complications
}

\author{
Authors: Alexander Reisinger, ${ }^{A}$ Susanne Vogt, ${ }^{B}$ Anna Essl, ${ }^{C}$ Ines Rauch, ${ }^{D}$ Florian Bangerl, ${ }^{D}$ Philipp Eller ${ }^{\mathrm{E}}$ and \\ Gerald Hackl $^{F}$
}

\section{Background}

Poppers are nitrite-containing liquids, which are inhaled for their aphrodisiac and hallucinogenic effects. Despite some cases of severe poisonings, poppers are often perceived as harmless by consumers. Inhalation and ingestion of poppers are well known, but, according to our literature review, intravenous abuse has not been reported before.

\section{Case presentation}

A 34-year-old man injected poppers intravenously for recreational purposes. He then suffered from dyspnoea and general discomfort. Upon arrival of emergency medical services, the patient was dyspnoeic with blue-grey skin colour and oxygen saturation was $82 \%$ on ambient air. Non-invasive ventilation was necessary, and he was transferred to the intensive care unit. Toluidine blue was administered because of a methaemoglobinaemia of $40 \%$ and methaemoglobin levels dropped to $0.4 \%$. He was discharged home after a 24-hour observation. We additionally analysed the contents of the poppers bottle: isopropyl nitrite, isopropanol and acetone were detected. Possible complications and the treatment regarding intravenous administration of poppers are discussed.

Conclusion

We present the first published case of intravenous poppers abuse. Our patient suffered from methaemoglobinaemia and was rapidly discharged after treatment with toluidine blue. No specific treatment regarding the contents of the poppers bottle, apart from isopropyl nitrite, was necessary.

KEYWORDS: Poppers, drug abuse, nitrites, methaemoglobinaemia DOI: 10.7861/clinmed.2019-0469

\section{Background}

Poppers are volatile inhalable liquids containing aromatic nitrites, which have euphoric and anal sphincter-relaxing effects. They

Authors: ${ }^{\text {A }}$ ritical care resident and research fellow, Medical University of Graz, Graz, Austria and Austrian Red Cross, Graz, Austria; ${ }^{\text {B }}$ forensic toxicology scientist, University Medical Center, Freiburg, Germany; ${ }^{C}$ emergency medical technician (paramedic), Austrian Red Cross, Graz, Austria; ${ }^{D}$ emergency medical technician, Austrian Red Cross, Graz, Austria; ${ }^{\mathrm{E}}$ critical care consultant, Medical University of Graz, Graz, Austria; 'F critical care consultant, Medical University of Graz, Graz, Austria and Austrian Red Cross, Graz, Austria became popular among men who have sex with men, frequently perceived as harmless by consumers and often sold stating other uses. ${ }^{1}$ The most commonly detected aromatic nitrites are amyl, butyl, isobutyl or isopropyl nitrite, but compositions vary. ${ }^{2,3}$ Intoxications caused by inhalation and oral ingestion have been reported comprehensively, but intravenous administration has not been described before. ${ }^{4,5}$

\section{Case presentation}

The emergency medical service was called regarding a 34-year-old man suffering from dyspnoea, general discomfort and palpitations. At his apartment, a dyspnoeic man with conspicuous blue-grey skin colour was encountered. The patient had fractionally self-administered $8 \mathrm{~mL}$ of poppers ('boooster'; Fig 1) intravenously over 1.5 hours for recreational purposes. He then suffered from severe dyspnoea and headache. Peripherally measured oxygen saturation was $82 \%$ on ambient air, respiratory rate was 20 breaths per minute and blood pressure was $130 / 80 \mathrm{mmHg}$. Electrocardiography showed a sinus tachycardia of 140 beats minute with slight anterior ST depression. The patient was fully oriented without focal neurological deficits. He received 15 litres of oxygen via a non-rebreather mask, but non-invasive ventilation (positive end-expiratory pressure 5 , assisted spontaneous breathing 8, fraction of inspired oxygen 1.0) was necessary. Oxygen saturation improved to $90 \%$ and he was transferred to the intensive care unit (ICU). Blood was obtained, which had a chocolate-brown colour. Blood gases showed a methaemoglobinaemia of $40 \%$ and an arterial oxygen saturation of $59 \%$. Metabolic acidosis (base excess $-2.6 \mathrm{mmol} / \mathrm{L}$ ) and respiratory alkalosis $\left(\mathrm{PaCO}_{2} 30 \mathrm{mmHg}\right)$ were present. Lactate was $4.4 \mathrm{mmol} / \mathrm{L}$ and $\mathrm{pH}$ was 7.44 . Laboratory analysis showed a leukocyte count of $13.0 \times 10^{9} / \mathrm{L}$, a C-reactive protein value of $2.3 \mathrm{mg} / \mathrm{L}$ (normal range $<10$ ), a procalcitonin level of $0.03 \mathrm{ng} / \mathrm{L}$ (normal range $0.00-0.50$ ), and normal kidney and liver function tests. Plasma osmolality and anion gap were within the normal range. Ethanol analysis and multidrug urine enzyme-immunoassay tests were negative. Echocardiography was unremarkable. The

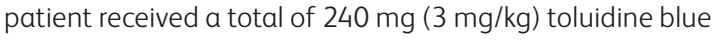
and methaemoglobin (Met- $\mathrm{Hb}$ ) level dropped to $0.8 \%$ within 4 hours. No further respiratory support was necessary, and he was discharged after 24 hours of observation. To understand the implications of intravenous injection of this drug, we analysed the contents of the 'boooster' bottle via headspace gas chromatography with flame ionisation detection and detected 


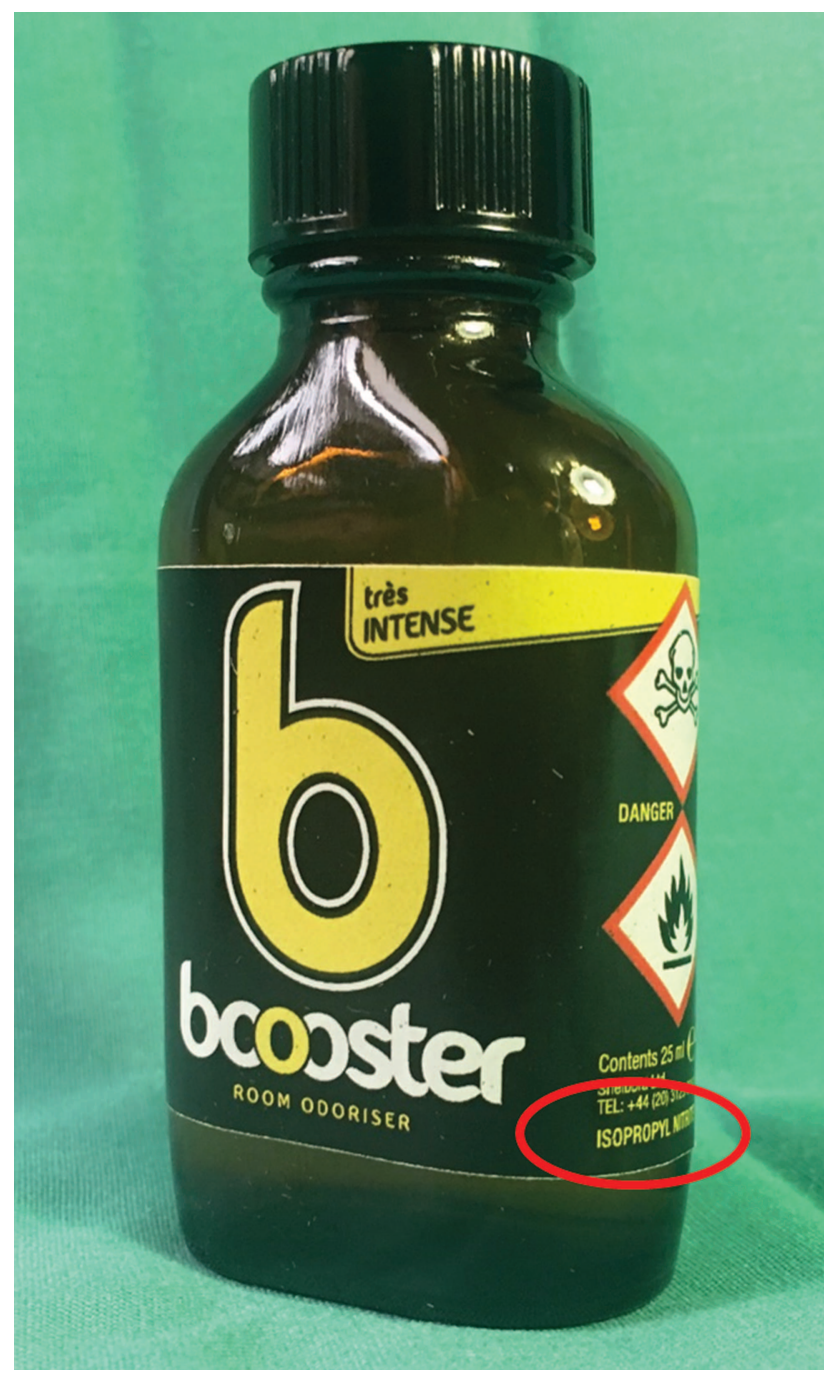

Fig 1. Photograph of the front of the poppers bottle 'boooster'. The content 'isopropyl nitrite' indicated on the bottle has been marked in red.

isopropyl nitrite, isopropanol (isopropyl alcohol; 2-propanol) and acetone (Fig 2). However, therapeutic management would have not been changed by those results.

\section{Discussion}

Severe poppers intoxications usually occur because of exaggerated inhalation or ingestion of the fluid. Oral intake compared to inhalation is associated with increased systemic toxicity, including life-threatening methaemoglobinaemia. ${ }^{4}$ Additionally, local acid burns in the mouth and oesophagus with the risk of perforation can occur. In the intravenous abuse in our patient, haemodynamic instability was expected, but our patient was normotensive without any relevant arrhythmias. He had fractionally administered the substance and a bolus application might have far greater effects on the circulatory system. Usually, nitrites induce a decrease of blood pressure, but the short duration of action makes prolonged hypotensive periods unlikely. ${ }^{4,6}$ Phosphodiesterase-5-inhibitors have been reported to be commonly abused in combination with poppers. Concurrent use may result in life-threatening hypotension. ${ }^{7,8}$ Initially, pulmonary fat embolism was considered, but it is unlikely that the small amount would cause any relevant pulmonary artery obstruction as, in comparison, fat boluses of $1.5 \mathrm{~mL} / \mathrm{kg}$ rarely cause embolism in lipid rescue therapy used for other intoxications. ${ }^{9}$ Brownish colour of the blood is a typical finding in methaemoglobinaemia. ${ }^{10}$ Physiologically, Met-Hb concentrations are about $1-2 \%$.

Responsible for the maintenance of these concentrations are erythrocyte cytochrome-b5 Met-Hb-reductase and nicotinamideadenine-dinucleotide-phosphate (NADPH) Met-Hb-reductase. High Met-Hb concentrations result in generalised tissue hypoxia with consecutive hyperlactataemia. Severity of symptoms usually correlates with the Met-Hb concentration (Table 1). ${ }^{11}$ In this case, despite Met- $\mathrm{Hb}$ concentration of $<50 \%$, metabolic acidosis with elevated lactate levels and severe respiratory symptoms were present. Therapeutically, toluidine or methylene blue are used as antidotes. Thereby the Met- $\mathrm{Hb}$ reduction through the NADPHMet- $\mathrm{Hb}$-reductase pathway can be increased four to six-fold. Methylene blue should be given intravenously at a dose of $1-2 \mathrm{mg} / \mathrm{kg}$ over 3-5 minutes, and, if ineffective, repeated at $1 \mathrm{mg} / \mathrm{kg}$ within 30 minutes. $^{12}$ If available, toluidine blue may be used instead of methylene blue as the effect onset and duration are similar, but a slightly better efficacy with fewer side effects has been reported. ${ }^{5,11,13}$ Hyperbaric oxygenation may be used as a treatment modality, particularly in patients who do not respond to therapeutic doses of methylene blue. ${ }^{12,14,15}$ Veno-arterial extracorporeal membrane oxygenation can be used in patients presenting with refractory cardio-circulatory shock, but it remains unclear whether it is possible to sufficiently load the erythrocytes with oxygen in the presence of methaemoglobinaemia.

Regarding the findings from the content analysis, acetone is a common solvent used to decrease viscosity and increase vapor pressure. It is necessary in many pharmaceutical production processes but can also, when inhaled, cause central nervous effects. The fast-evaporating isopropanol is the hydrolysis product of isopropyl nitrite and often used in various disinfectants. The exact toxic doses are unknown but, when ingested, lethal doses of $>100 \mathrm{~mL}$ and $3.4 \mathrm{~mL} / \mathrm{kg}$ have been reported. Nevertheless,
Fig 2. Headspace gas chromatography with flame ionisation detection analysis of the 'boooster' contents. The left-most and highest peak is isopropyl nitrite, the middle peak is isopropanol and the right peak is acetone.

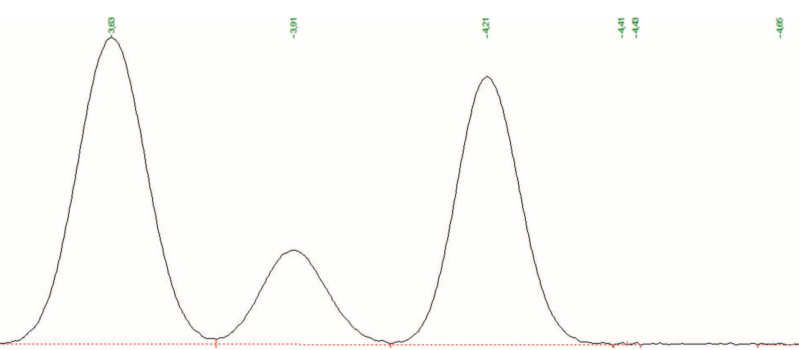


Table 1. Clinical findings in patients with

methaemoglobinaemia ${ }^{11}$

$\begin{array}{ll}\begin{array}{l}\text { Methaemoglobin } \\ \text { concentration } \\ 1-3 \%\end{array} & \text { Clinical findings } \\ 3-15 \% & \text { None } \\ & \begin{array}{l}\text { Possibly none; pulse oximeter will read } \\ \text { low oxygen saturations } \\ \text { Cyanosis (central and peripheral); not } \\ \text { improving with oxygen administration }\end{array} \\ & \begin{array}{l}\text { Dyspnoea, headache, fatigue, dizziness } \\ \text { and syncope }\end{array} \\ 50-50 \% & \begin{array}{l}\text { Tachypnoea, metabolic acidosis, } \\ \text { arrhythmias, seizures, central nervous } \\ \text { system depression and coma } \\ \text { Grave hypoxic symptoms and death }\end{array}\end{array}$

these doses are not well validated, and the cut-off regarding toxic intravenous doses is unknown. ${ }^{16-18}$ Clinically, isopropanol poisoning manifests with vomiting, diarrhoea, confusion, seizures and cardio-circulatory shock. ${ }^{16,19}$ Haemodialysis can be used to remove isopropanol. Ethanol or fomepizole are contraindicated as the degradation product (acetone) is less toxic then isopropanol itself. ${ }^{16,20}$ The amount injected by our patient is, in comparison, rather small and clinical presentation made a relevant isopropanol poisoning unlikely.

\section{Conclusion}

We present a case of intravenous injection of poppers, which led to methaemoglobinaemia and respiratory failure but did not affect haemodynamic stability. We suspect that intravenous bolus administration of poppers may lead to greater haemodynamic complications than the fractionated intravenous abuse observed in our case. The content analysis of the poppers bottle revealed isopropyl nitrite, isopropanol and acetone. Thereof, only the isopropyl nitrite required specific treatment.

\section{Acknowledgements}

We thank Stephan T Palm from Northeastern University, Boston, Massachusetts, for proofreading and spell-checking the manuscript and are very grateful for his time and input.

\section{Ethical approval}

Approval from the local ethics committee was obtained (ethics committee Graz, vote number 31-566 ex 18/19).

\section{References}

1 Romanelli F, Smith KM, Thornton AC, Pomeroy C. Poppers: epidemiology and clinical management of inhaled nitrite abuse. Pharmacotherapy 2004;24:69-78.

2 Vogt S, Angerer V, Kempf J, Auwärter V. Analysis of 'poppers' products and analytical detectability of a single use of "poppers". Toxichem Krimtech 2015:82:218-9.
3 Rewbury R, Hughes E, Purbrick R, Prior S, Baron M. Poppers: legal highs with questionable contents? A case series of poppers maculopathy. Br J Ophthalmol 2017;101:1530-4.

4 Bernasconi B, Konrad C, Fischer S. [Case report - a dangerous intoxication after ingestion of alkyl nitrite ('poppers')]. Anasthesiol Intensivmed Notfallmed Schmerzther 2014:49:654-8.

5 Janssens $U$, Hillen S, Janssens T, Grafe ]. [Methaemoglobinaemia after inhalation of poppers]. Med Klin Intensivmed Notfmed 2019;114:345-9.

6 Sheena Y, Baston EL, Downs A, Chester DL. A sticky situation: methaemaglobinaemia in a hand trauma patient. BMJ Case Rep 2012;2012:bcr2012007196.

7 Giorgetti R, Tagliabracci A, Schifano F, Zaami S, Marinelli E, Busardo FP. When "Chems" meet sex: A rising phenomenon called "ChemSex". Curr Neuropharmacol 2017;15:762-70.

8 Webb DJ, Freestone S, Allen MJ, Muirhead GJ. Sildenafil citrate and blood-pressure-lowering drugs: results of drug interaction studies with an organic nitrate and a calcium antagonist. Am J Cardiol 1999:83:21C-8C.

9 Hayes BD, Gosselin S, Calello DP et al. Systematic review of clinical adverse events reported after acute intravenous lipid emulsion administration. Clin Toxicol (Phila) 2016;54:365-404.

10 Gamgee A, Fraser TR, Rutherford W. Report on the progress of physiology: From 1st March to 1st August, 1868. J Anat Physiol 1868:3:207-41.

11 Wright RO, Lewander WJ, Woolf AD. Methaemoglobinaemia: etiology, pharmacology, and clinical management. Ann Emerg Med 1999;34:646-56.

12 Hunter L, Gordge L, Dargan PI, Wood DM. Methaemoglobinaemia associated with the use of cocaine and volatile nitrites as recreational drugs: a review. Br J Clin Pharmacol 2011;72:18-26.

13 Kiese M, Lorcher W, Weger N, Zierer A. Comparative studies on the effects of toluidine blue and methylene blue on the reduction of ferrihaemoglobin in man and dog. Eur J Clin Pharmacol 1972:4:115-8.

14 Lindenmann J, Matzi V, Kaufmann P et al. Hyperbaric oxygenation in the treatment of life-threatening isobutyl nitriteinduced methaemoglobinaemia-a case report. Inhal Toxicol 2006;18:1047-9.

15 Lindenmann J, Fink-Neuboeck N, Schilcher G, Smolle-Juettner FM. Severe methaemoglobinaemia treated with adjunctive hyperbaric oxygenation. Diving Hyperb Med 2015;45:132-4.

16 Lacouture PG, Wason S, Abrams A, Lovejoy FHJr. Acute isopropyl alcohol intoxication. Diagnosis and management. Am J Med 1983;75:680-6.

17 Slaughter RJ, Mason RW, Beasley DM, Vale JA, Schep LJ. Isopropanol poisoning. Clin Toxicol (Phila) 2014;52:470-8.

18 Kraut JA, Mullins ME. Toxic alcohols. N Engl J Med 2018;378:270-80.

19 Steinmann D, Faber T, Auwarter V, Heringhaus C. [Acute intoxication with isopropanol]. Anaesthesist 2009;58:149-52.

20 Abramson S, Singh AK. Treatment of the alcohol intoxications: ethylene glycol, methanol and isopropanol. Curr Opin Nephrol Hypertens 2000;9:695-701.

Address for correspondence: Dr Alexander Reisinger, Intensive Care Unit, Department of Internal Medicine, Medical University of Graz, Auenbruggerplatz 15, 8036 Graz, Austria. Email: alexander.reisinger@medunigraz.at 